\title{
Cross-Cultural Adaptation, Validation, and Reliability Testing of the Modified Oswestry Disability Questionnaire in Persian Population with Low Back Pain
}

\author{
Aslan Baradaran ${ }^{1}$, Mohammad H. Ebrahimzadeh ${ }^{1}$, Ali Birjandinejad ${ }^{1}$, Amir Reza Kachooei ${ }^{1,2}$ \\ ${ }^{1}$ Orthopedic Research Center, Mashhad University of Medical Sciences, Mashhad, Iran \\ ${ }^{2}$ Orthopaedic Hand and Upper Extremity Service, Massachusetts General Hospital, Harvard Medical School, Boston, MA, USA
}

\section{Study Design: Prospective study.}

Purpose: We aimed to validate the Persian version of the modified Oswestry disability questionnaire (MODQ) in patients with low back pain.

Overview of Literature: Modified Oswestry low back pain disability questionnaire is a well-known condition-specific outcome measure that helps quantify disability in patients with lumbar syndromes.

Methods: To test the validity in a pilot study, the Persian MODO was administered to 25 individuals with low back pain. We then enrolled 200 consecutive patients with low back pain to fill the Persian MODQ as well as the short form 36 (SF-36) questionnaire. Convergent validity of the MODO was tested using the Spearman's correlation coefficient between the MODO and SF-36 subscales. Intraclass correlation coefficient (ICC) and Cronbach's a coefficient were measured to test the reliability between test and retest and internal consistency of all items, respectively.

Results: ICC for individual items ranged from 0.43 to 0.80 showing good reliability and reproducibility of each individual item. Cronbach's a coefficient was 0.69 showing good internal consistency across all 10 items of the Persian MODO. Total MODO score showed moderate to strong correlation with the eight subscales and the two domains of the SF-36. The highest correlation was between the MODQ and the physical functioning subscale of the SF-36 $(r=-0.54, p<0.001)$ and the physical component domain of the SF-36 $(r=-0.55$, $p<0.001$ ) showing that MODQ is measuring what it is supposed to measure in terms of disability and physical function.

Conclusions: Persian version of the MODQ is a valid and reliable tool for the assessment of the disability following low back pain.

Keywords: Persian; Reliability; Modified Oswestry disability questionnaire; Validity; Low back pain

\section{Introduction}

Self-reported measures of disability are widely used to measure the outcome of the treatment received for low back pain [1]. Modified Oswestry low back pain disability questionnaire $(\mathrm{ODQ})$ is a well-known condition-specific outcome measure that helps quantify disability in patients with lumbar syndromes [2]. Because of the low response

Received Jul 14, 2015; Accepted Jul 31, 2015

Corresponding author: Amir Reza Kachooei

Orthopedic Research Center, Ghaem Hospital, Mashhad University of Medical Sciences, Mashhad 99199-91766, Iran

Tel: +98-513-801-2638, Fax: +98-513-841-7453, E-mail: akachooei@mgh.harvard.edu, kachoeear@mums.ac.ir 
rate to items asking about gender, Fritz and Irrgang [3] made this modification on the original questionnaire. They replaced the gender item with an item describing employment and homemaking. The modified ODQ consists of 10 items each scored from 0 to 5 . The total is calculated through multiplying the sum of the scores by 2 , giving a range of 0 to 100; a higher score reflects higher disability.

Persian is one of the most commonly spoken languages in the middle-east region including Iran, Afghanistan, Tajikistan, and some parts of Iraq and Pakistan. Asking patients about their sexual behavior may not be acceptable in some cultures in these countries. However, to protect the psychometric properties of this tool, cross-cultural adaptation is necessary $[4,5]$. Thus, we aimed to validate and cross-culturally adapt the translated Persian version of the modified ODQ for Persian-speaking population in gauging treatment outcome for low back pain.

Table 1. Characteristics of patients with lower back pain $(n=200)$

\begin{tabular}{lc}
\hline Demographics & Number (\%) \\
\hline Age, mean (SD) & $40(13)$ \\
\hline Sex & \\
\hline Male & $84(42)$ \\
\hline Female & $116(58)$ \\
\hline Career & \\
\hline Jobless & $5(2.5)$ \\
\hline Laborer & $21(11)$ \\
\hline Employee & $31(16)$ \\
\hline Self-employment & $46(23)$ \\
\hline Houskeeper & $87(44)$ \\
\hline Student & $6(3)$ \\
\hline Collegian & $4(2)$ \\
\hline Education & \\
\hline School & $47(24)$ \\
\hline Highschool & $35(18)$ \\
\hline Diploma & $61(31)$ \\
\hline Undergraduate & $35(18)$ \\
\hline Postgraduate & $22(11)$ \\
\hline Involved side & $36(18)$ \\
\hline Right & $48(24)$ \\
\hline Left & $116(58)$ \\
\hline Bilateral & \\
\hline Val & \\
\hline
\end{tabular}

Values are presented as mean \pm standard deviation (SD) or number (\%).

\section{Materials and Methods}

\section{Patients}

In this Institutional Review Board approved study, we enrolled 200 consecutive patients from the spine clinic from September 2014 to February 2015. Patients with low back pain, aged 18 years or older, with symptom duration of more than 2 months were included in this study. Patients with neoplasm, radiating pain from other sites, infection, and systemic inflammatory disease were excluded (Tables 1,2). All participants were literate native Persian speakers.

\section{Translation}

Following Beaton's guidelines for cross-cultural adaptation of the modified ODQ, three independent Persianspeaking individuals including two general orthopedic

Table 2. Average functional scores of patients with lower back pain $(\mathrm{n}=200)$

Variable $\quad$ Mean (SD)

\section{SF-36}

\begin{tabular}{|l|l|}
\hline Physical functioning & $42(2.1)$ \\
\hline Role physical & $31(2.8)$ \\
\hline Bodily pain & $30(1.9)$ \\
\hline General health & $45(1.5)$ \\
\hline Vitality & $52(1.4)$ \\
\hline Social functioning & $45(2.4)$ \\
\hline Role emotional & $33(3.1)$ \\
\hline Mental health & $49(1.8)$ \\
\hline Physical component summary & $33(9.5)$ \\
\hline Mental component summary & $42(9.1)$ \\
\hline Modified Oswestry & \\
\hline Pain intensity & $3.4(1.4)$ \\
\hline Personal care & $2.3(1.2)$ \\
\hline Lifting & $3.6(1.5)$ \\
\hline Walking & $3.2(1.4)$ \\
\hline Sitting & $2.8(1.2)$ \\
\hline Standing & $3.8(1.5)$ \\
\hline Sleeping & $2.5(1.5)$ \\
\hline Social life & $3.2(1.6)$ \\
\hline Traveling & $3.1(1.1)$ \\
\hline Employment/homemaking & $2.8(1.1)$ \\
\hline Standad devation
\end{tabular}

SD, standard deviation. 
surgeons and one professional English tutor with no medical background translated the original English version of the modified ODQ to Persian (also known as Farsi) [4]. These three translations were then reviewed and reconciled into a single Persian modified ODQ version. In the next step, a native American English speaker fluent in Persian that was not aware of the original English version of the MODQ translated this Persian version back into English and the conformity this version with the original English version of the MODQ was measured.

Agreement of the Persian and the original English modified ODQ was evaluated in the presence of the authors and professional translators addressing the "back to English" translation. After this, we reached a consensus for the penultimate version of our Persian MODQ. To test the validity of this version in a pilot study, this Persian modified ODQ was administered to 25 individuals with low back pain. Minimal obstacles in understanding the questionnaire were rectified and the final version was designed (Suppl. Fig. 1).

\section{Modified Oswestry disability questionnaire}

In 1980, Fairbank et al. [2] created and introduced the Oswestry low back pain disability index. This questionnaire was applied for many years and was reported to be reliable, valid, and compatible with conditions with low back pain $[2,6]$. However, several modifications have been done on this tool $[3,6]$. Because of the low response rate to questions about sex life, the last modified ODQ replaced these questions with the ones for employment/home making [7]. This tool is a self-administered 10-item questionnaire that takes less than 5 minutes to complete. Items are mainly questioning about pain intensity related to the activities of daily living. Each item is responded using six statements describing an escalating level of severity to a particular activity scoring from $0-5$. To report the raw scores in percentage, all items must be added together and multiplied by 2 to show the percentage of disability with the higher score representing higher pain intensity and disability [2].

\section{Psychometric properties}

Intraclass correlation coefficient (ICC) and Cronbach's a coefficient were used to test the reliability between test and retest and internal consistency of all items, respectively. Convergent validity of the modified ODQ was tested by using the validated Persian short form 36 (SF-36) survey and applying the Spearman's correlation coefficient between the modified ODQ and SF-36 subscales [8].

\section{Results}

The total modified ODQ score showed good reliability with a high and significant ICC between test and retests (Table 3). ICC for individual items mainly ranged from $0.43-0.80$ showing a good reliability and reproducibility of each individual item (Table 3).

Cronbach's a coefficient was 0.69 showing good internal

Table 3. Reliability testing of the modified Oswestry questionnaire (test, $n=200$; retest, $n=89$ )

\begin{tabular}{|c|c|c|c|c|c|}
\hline \multirow{2}{*}{ Item } & \multirow{2}{*}{ Question } & \multicolumn{3}{|c|}{ Intraclass correlation coefficient (ICC) } & \multirow{2}{*}{ Cronbach's a } \\
\hline & & ICC & $95 \%$ Confidence interval & $p$-value & \\
\hline 1 & Pain intensity & 0.619 & $0.40-0.76$ & $<0.001$ & \\
\hline 2 & Personal care & 0.687 & $0.52-0.80$ & $<0.001$ & \\
\hline 3 & Lifting & 0.796 & $0.69-0.87$ & $<0.001$ & \\
\hline 4 & Walking & 0.161 & -0.28 to 0.45 & 0.208 & \\
\hline 5 & Sitting & 0.432 & $0.15-0.62$ & 0.003 & \\
\hline 6 & Standing & 0.686 & $0.52-0.79$ & $<0.001$ & \\
\hline 7 & Sleeping & 0.585 & $0.36-0.73$ & $<0.001$ & \\
\hline 8 & Social Life & 0.666 & $0.48-0.78$ & $<0.001$ & \\
\hline 9 & Traveling & 0.722 & $0.58-0.82$ & $<0.001$ & \\
\hline 10 & Employment/homemaking & 0.488 & $0.23-0.66$ & 0.001 & \\
\hline \multicolumn{2}{|c|}{ Total modified Oswestry } & 0.676 & $0.51-0.79$ & $<0.001$ & 0.69 \\
\hline
\end{tabular}


Table 4. Convergent validity expressed by Spearman's rho correlation coefficient between subscales of the Persian modified Oswestry and subscales of the SF-36 $(\mathrm{n}=200)$

Variable Modified Oswestry

\begin{tabular}{lc}
\hline SF-36 & \\
\hline Physical functioning & $-0.54^{\mathrm{al}}$ \\
\hline Role physical & $-0.33^{\mathrm{a}}$ \\
\hline Bodily pain & $-0.52^{\mathrm{a})}$ \\
\hline General health & $-0.36^{\mathrm{a}}$ \\
\hline Vitality & $-0.27^{\mathrm{a})}$ \\
\hline Social functioning & $-0.35^{\mathrm{a}}$ \\
\hline Role emotional & $-0.40^{\mathrm{a}}$ \\
\hline Mental health & $-0.18^{\mathrm{b})}$ \\
\hline PCS & $-0.55^{\mathrm{a}}$ \\
\hline MCS & $-0.31^{\mathrm{a})}$ \\
\hline
\end{tabular}

SF-36, short form 36; PCS, physical condition scale; MCS, mental condition scale.

${ }^{a}$ Correlation is significant at the 0.05 level (2-tailed); ${ }^{b}$ Correlation is significant at the 0.01 level (2-tailed).

consistency across all 10 items for the Persian modified ODQ. Cronbach's a was almost the same at the first and second visit for the total measure (Table 3).

Total modified ODQ showed moderate to strong correlation with the eight subscales and the two domains of the SF-36. The highest correlation was between the modified ODQ and the physical functioning subscale of the SF-36 $(r=-0.54, p<0.001)$ and the physical component domain of the SF-36 $(r=-0.55, p<0.001)$ showing that a high dependability of MODQ in measuring disability and physical function (Table 4).

\section{Discussion}

The aim of our study was to test the validity and reliability of the Persian version of modified ODQ for the Persian speaking population with low back pain conditions. We confirmed the validity and reliability of the Persian modified ODQ and usefulness of this instrument in quantifying the functional disability.

One of the limitations to our study is that we administered the modified ODQ to patients who previously had lumbar surgery regardless of the time passed after the surgery. Another limitation of our current study is that we validated the region-specific modified ODQ in respect to a more general measure such as SF-36. However, SF-36 is an appropriate patient-based questionnaire proved to be useful in validating the questionnaires while representing the quality of life [9].

The thorough questionnaire demonstrated good reliability, good internal consistency, and confirmed convergent validity. By comparing the modified ODQ with the SF-36 questionnaire, the convergent validity was tested that showed a moderate to strong correlation. Both reliability and validity level of the Persian version were as high as the original English version. The high and significant correlation between modified ODQ and subscales of function in SF-36 demonstrated the conformity of their context in that both are measuring what they are supposed to measure namely disability and physical function.

Good test-retest reliability of the present study strongly corresponded to previous studies of the Modified version of the ODQ [3,10]. Baker et al. [11] reported high reliability of the modified ODQ $(r=0.89)$. Comparing the modified ODQ and the Quebec back pain disability scale (QUE), Fritz and Irrgang [3], showed superior reliability of the modified ODQ with ICC for the modified ODQ of 0.90 (95\% confidence interval [CI ], 0.78-0.96) and for the QUE of 0.55 (95\% CI, 0.20-0.78). The ICC for testing the reliability of individual items of the Thai version ranged from $0.82-0.99$ and the ICC for the total score was 0.98 showing excellent reliability [10].

\section{Conclusions}

Similar to those of prior validation studies, Persian version of modified ODQ was found to be valid and reliable for low back pain disability assessment in an Iranian population. For a patient centered tool, slight differences tailored for cultural adaptation are acceptable as far as the results prove to be valid and reliable [12].

\section{Conflict of Interest}

No potential conflict of interest relevant to this article was reported.

\section{Supplementary Materials}

Suppl. Fig. 1. Persian version of the modified Oswestry disability questionnaire is shown that is validated. Supplementary material can be found at http://www.asianspinejournal.org/src/sm/asj-10-215-s001.pdf. 


\section{References}

1. Fairbank JC, Pynsent PB. The Oswestry Disability Index. Spine (Phila Pa 1976) 2000;25:2940-52.

2. Fairbank JC, Couper J, Davies JB, O'Brien JP. The Oswestry low back pain disability questionnaire. Physiotherapy 1980;66:271-3.

3. Fritz JM, Irrgang JJ. A comparison of a modified Oswestry Low Back Pain Disability Questionnaire and the Quebec back pain disability scale. Phys Ther 2001;81:776-88.

4. Beaton DE, Bombardier C, Guillemin F, Ferraz MB. Guidelines for the process of cross-cultural adaptation of self-report measures. Spine (Phila Pa 1976) 2000; 25:3186-91.

5. Guillemin F, Bombardier C, Beaton D. Cross-cultural adaptation of health-related quality of life measures: literature review and proposed guidelines. J Clin Epidemiol 1993;46:1417-32.

6. Beurskens AJ, de Vet HC, Koke AJ. Responsiveness of functional status in low back pain: a comparison of different instruments. Pain 1996;65:71-6.

7. Stratford PW, Binkley J, Solomon P, Gill C, Finch E. Assessing change over time in patients with low back pain. Phys Ther 1994;74:528-33.

8. Motamed N, Ayatollahi AR, Zare N, SadeghiHassanabadi A. Validity and reliability of the Persian translation of the SF-36 version 2 questionnaire. East Mediterr Health J 2005;11:349-57.

9. Kachooei AR, Ebrahimzadeh MH, Erfani-Sayyar R, Salehi M, Salimi E, Razi S. Short Form-McGill Pain Questionnaire-2 (SF-MPQ-2): A Cross-Cultural Adaptation and Validation Study of the Persian Version in Patients with Knee Osteoarthritis. Arch Bone Jt Surg 2015;3:45-50.

10. Sakulsriprasert P, Vachalathiti R, Vongsirinavarat $M$, Kantasorn J. Cross-cultural adaptation of modified Oswestry Low Back Pain Disability Questionnaire to Thai and its reliability. J Med Assoc Thai 2006;89: 1694-701.

11. Baker D, Pynsent PB, Fairbank JC. The Oswestry disability index revisited: its reliability, repeatability and validity, and a comparison with the St Thomas's Disability Index. In: Roland MO, Jenner JR, editors. Back pain: new approaches to rehabilitation and education. Manchester: Manchester University Press; 1989. p.174-86.

12. Ebrahimzadeh MH, Birjandinejad A, Golhasani F, Moradi A, Vahedi E, Kachooei AR. Cross-cultural adaptation, validation, and reliability testing of the Shoulder Pain and Disability Index in the Persian population with shoulder problems. Int J Rehabil Res 2015;38:84-7. 